\title{
On the interpretation of working memory span in adults
}

\author{
JOHN N. TOWSE \\ Royal Holloway, University of London, London, England \\ GRAHAM J. HITCH \\ University of Lancaster, Lancaster, England \\ and \\ UNA HUTTON \\ Royal Holloway, University of London, London, England
}

\begin{abstract}
Experimental research into children's working memory span has shown that retention duration contributes substantially to span performance, while processing efficiency need not be related to concurrent memory load (Towse, Hitch, \& Hutton, 1998). These findings have been used to argue for a model of working memory span that emphasizes time-based forgetting rather than the popular resource-sharing or tradeoff framework. The present paper considers whether adults perform working memory span tasks in a qualitatively different way. Data from reading span and operation span tasks show that adults' performance can be distinguished from that of children, but also that a task-switching model of working memory span can explain some important aspects of performance.
\end{abstract}

From a venerable lineage of approaches to the retentive capacity of the mind, considerable contemporary interest resides in the notion of working memory (e.g., Baddeley, 1986), often thought of as a dynamic system with separable components. Part of the enthusiasm for working memory arises from the idea that retention is an integral part of mental activities (Baddeley \& Hitch, 1974; Hitch \& Baddeley, 1976). This view has been supported by empirical evidence that on-line memory processes are closely tied to successful cognitive performance. Baddeley and Hitch (Experiment 3), for example, found that a substantial concurrent memory load impaired the speed of reasoning processes, with the degree of impairment varying as a function of the difficulty of the reasoning involved. Daneman and Carpenter (1983) have argued that working memory performance shapes the ability to understand ambiguity in texts (see also Miyake, Just, \& Carpenter, 1994; Tirre \& Peña, 1992), while Adams and Hitch (1997) examined how children's arithmetic is shaped by the memory requirements of carry operations.

To capture the postulated interdependence between processing and storage activities, a series of working memory span tasks have been developed. These include counting span (Case, Kurland, \& Goldberg, 1982), reading span

This work was supported by Economic and Social Research Council Grant R0002361 13. We are grateful for comments from anonymous reviewers. The software for the operation span and reading span tests is available at http://www.pc.rhbnc.ac.uk/cdrg/cdrg.html. Correspondence should be addressed to J. N. Towse, Department of Psychology, Royal Holloway, University of London, Egham, Surrey TW20 0EX, U.K. (e-mail: j.towse@rhbnc.ac.uk).
(Daneman \& Carpenter, 1980), and operation span (Turner \& Engle, 1989), where individuals perform a series of mental activities and attempt to retain a component of each problem. Thus, in counting span, the participant might enumerate a series of arrays and subsequently recall their totals. These types of tasks are taken to measure working memory capacity, which is argued to reflect the balance of mental "resources" divided between processing and retention of information. Quite what these resources are is often left unspecified (though see Conway \& Engle, 1994, for one approach to this issue). Nonetheless, memory functions are thought to be compromised by computationally intensive concurrent processing. Likewise, individuals with low processing efficiency are thought to supply fewer resources for memory. Evidence that working memory span, compared with standard digit or word span, affords a good predictor of cognitive performance (Daneman \& Carpenter, 1980; Engle, Tuholski, Laughlin, \& Conway, 1999; Kyllonen \& Christal, 1991) is seen as additional confirmation of how working memory reflects an architecture distinct from that of short-term memory (Daneman, 1995).

Although it is usual to stress the importance of resource sharing for working memory or "complex span" tasks, the latter can be distinguished from "simple span" tasks like word span in a number of ways. ${ }^{1}$ In some studies, these types of memory test differ in terms of the nature of the material to be remembered or the size of the pool of items from which memory stimuli are drawn (La Pointe \& Engle, 1990). Working memory tasks typically involve a much longer presentation length and an uneven interstimulus interval (because the generation of memory stimuli is inter- 

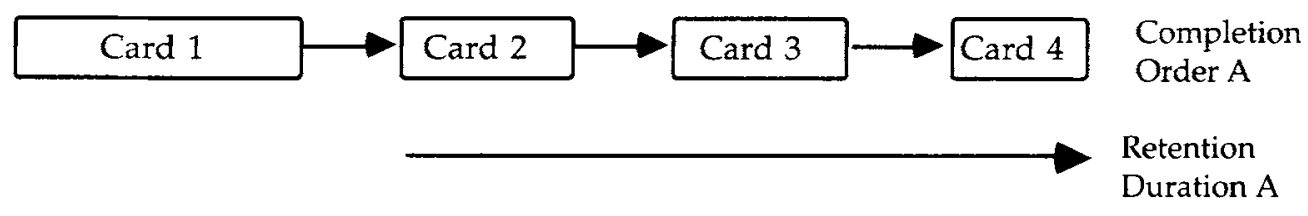

Retention
Duration A

Retention

Duration B

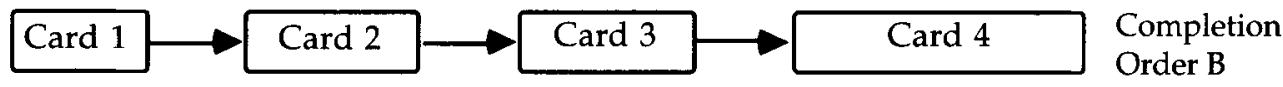

Figure 1. Schematic illustration of the manipulation of card completion order used in the present experiment. Total completion time and work done is equivalent for Completion Order $A$ and Completion Order B since the ensemble of activity is the same. However, arrows indicate the time period during which retention is required, and this shows that Completion Order $B$ involves greater retention requirements by virtue of starting earlier than Completion Order $\mathrm{A}$.

spersed with other processing), while the processing task provides through-list distraction, and span scores are generally smaller. Reading span and word span commonly involve different levels of semantic or elaborated processing (see Craik \& Tulving, 1975), in part because working memory stimuli are often self-generated rather than experimentally imposed (though this is not always the case). At recall, the processing activity of a working memory span task (e.g., the sentence read for comprehension) potentially serves as both a cue and distractor to the item to be retrieved. Further, memory measures may differ in terms of the opportunity for particular strategic activities such as articulatory rehearsal.

The preceding summary by no means exhausts the differences between memory tasks, and some of these may not be important. However, especially when considered in concert, they suggest how there is likely to be more to working memory span than a simple resource-sharing strategy. Indeed, Towse and Hitch (1995) argued that it was unnecessary to postulate resource sharing at all in order to explain why children's counting span varied with measures of processing efficiency. An alternative hypothesis stresses the impact of time-based forgetting. That is, difficult processing tasks may be associated with reduced memory not because of the large processing demand per se, but rather because of the additional completion time involved in difficult tasks. Supporting this alternative account, Towse and Hitch found comparable counting spans for materials matched in duration but differing in cognitive demand (see also Halford, Maybery, O'Hare, \& Grant, 1994).

Towse et al. (1998) provided further assessment of the importance of retention duration and resource sharing among 8- to 11 -year-olds. In three experiments, children performed counting span, operation span, and reading span tasks. The ensemble or set of processing operations was held constant, and the completion order of individual activities ("cards") was varied. A trial comprised either a short-duration card as the first activity and a long- duration card as the last activity, or vice versa. Since it is the processing products that are remembered, only when the first card is complete does the memory load start. Consequently, a trial that terminates with a long final card requires a greater retention interval than a trial that terminates with a short final card (Figure 1). This allows retention interval to be varied while keeping constant the overall work done.

Towse et al. (1998) found that, for all three working memory tasks, span was significantly impaired when retention duration was extended, even though the overall cognitive work done was equivalent. At the same time, analyses indicated that processing efficiency was not consistently affected by the concurrent memory load. Comparison of the same processing operations performed at the beginning of the trial (where there was no concurrent memory load) and at the end of the trial (where memory load was higher because all previous cards needed to be remembered) revealed that processing speed actually increased with memory load on the counting span task, remained invariant on the reading span task, and decreased on the operation span task- but only in one of two experiments, and for that study only in one particular task administration order. In sum, there was no systematic evidence that memory load affected processing efficiency.

The finding that retention time influenced span, together with the finding that memory load did not influence processing, was seen to favor the resource-switching or task-switching model of Towse and Hitch (1995). A core assumption of this model is that processing and retention need not interfere. While this contrasts with resource-sharing models, it explains the lack of tradeoff between memory and processing efficiency. A second assumption is that forgetting increases with the amount of time spent on the processing component of the span task. This explains the effects of manipulating retention duration. Since simple resource-sharing models do not take account of forgetting time, they do not predict the differences that were obtained, constraining their explanatory 
power. In more general terms, the task-switching model suggests that processing difficulty affects memory functions because difficulty is usually relevant to task completion time, affecting the amount of forgetting that occurs within the system. Likewise, individual differences between processing efficiency and span are interpreted in terms of how processing speed affects retention requirements for span items (e.g., children counting quickly can proceed through more cards before memory items become inaccessible).

However, the evidence for the task-switching model, which does not call on a general resource mechanism to explain performance, is based so far on children's performance. Engle, Cantor, and Carullo (1992) argued that among adults, processing speed does not account for individual differences in working memory capacity. In a regression-based analysis, Conway and Engle (1996) suggested that processing completion time did not explain performance at an operation span task titrated for task difficulty for each experimental participant. What should one make of this difference between children and adults? As pointed out by Towse and Hitch (1995) and Towse et al. (1998), there may be a developmental progression toward resource-sharing strategies. An alternative is that experimental effects and developmental change may need to be distinguished from individual differences among adults (Engle, 1996).

As a step toward bridging the gap between data from children and adults, and as a further step toward assessing task-switching and resource-sharing frameworks, adults were asked to complete the operation span and reading span tasks previously administered to children (Towse et al., 1998). To facilitate age-related comparisons, we used identical materials. Even though the tasks were designed for 8- to 11 -year-olds (involving the completion of relatively simple sums and sentences), presenting them to adults was not a problem once they had been briefed about their developmental origins. Independent tests of processing speed were also administered, since this allowed a further examination of the extent to which working memory performance was related to general processing mechanisms.

The present study allows for two tests of working memory mechanisms in adults: (1) a test for the impact of retention interval on span, predicted by the task-switching model but not by the simple resource-sharing model; and (2) a test for the impact of memory load on processing, predicted by the resource-sharing model of span but not by the task-switching model.

\section{METHOD}

\section{Design and Participants}

The experiment was completed by an opportunity sample of 30 adults (both graduates and nongraduates) who were paid an honorarium $(\mathfrak{E} 3)$ and whose mean age was 34 years (range $=17-65$ years). All were naive to the working memory span literature. The effect of card completion order (a long final or short final condition) was a within-subjects manipulation, as was the working memory span task (reading span and operation span). Thus, all participants were administered two reading span tests (always presented together) and two operation span tests (also presented together) with the order of span tests varying between individuals. They also completed both forms of the digit-matching test (following operation span assessment) and the picture-matching test (following reading span assessment), taken from the Kit of Factor-Referenced Cognitive Tests (Ekstrom, French, Harmen, \& Dermen, 1976). All testing was done in a single session.

\section{Procedure}

The experimental procedure followed closely that used in Towse et al.'s (1998) Experiment 3. Working memory span was assessed on a Macintosh PowerBook 5300c with a 10.25 -in. TFT wide-angle screen. The working memory span tests began with three cards to process and remember (in contrast with children's assessments, which began with two-card sets) and continued until two or more errors were made at a span level, or when a seven-card set was successfully completed on two of three occasions (the maximum level attainable, achieved on 5 of 120 assessments). Participants were told that the materials had been originally devised for children. For reading span they were asked to complete a sentence with the appropriate word. Examples of the sentences (and expected completions) are "Ben clapped his ... (hands)" and "If I hear a funny joke it makes me smile and ... (laugh)." For the operation span task, participants solved an arithmetic equation. For example, an adult might be presented with the following sequence, each problem appearing once the preceding one had been answered:

$$
\begin{aligned}
& 7+1= \\
& 6-1-1= \\
& 4+1+1-1=
\end{aligned}
$$

The participant was not required to vocalize the sum or sentence being processed, but did provide an oral response to each question (which the experimenter entered via an external keyboard) and then attempted to recall the answers derived for each card (e.g., 8, 4, 5) they had. In the above example, the first card involves a short processing operation, the last card a long operation. In addition to assessing span with a long final card, a short final condition (where the first and last cards are swapped over) was also presented. The complete list of sentences and sums is provided in Towse, Hutton, and Hitch (1997) and Hutton, Towse, and Hitch (1997), respectively.

It was stressed to each person that he/she should not say anything between reading/calculation problems (i.e., should not rehearse). By way of reinforcing this, participants were required to attend and respond to the card as soon as it appeared on the screen, and the experimenter monitored the participant for signs of rehearsal. Correct memory responses always corresponded to the items produced earlier in the trial, even where these items were not the correct solutions to the processing task.

\section{RESULTS}

\section{Experimental Effects}

The manipulation of final card (short final or long final) only affected where long and short cards appeared in the sequence, but not what the sequence as a whole entailed. Consequently, the time to complete a working memory trial, expressed as seconds per card and averaging across position, should be the same for both completion orders. Table 1 details the completion time for the two working memory span tasks. As a manipulation check, an 
Table 1

The Effect of Placing Short and Long Cards at the Beginning and End of Reading and Operation Span Sequences, as Measured by Overall Processing Time ( $T$, in Seconds) and Memory Performance

\begin{tabular}{lccccc}
\hline & \multicolumn{2}{c}{$\begin{array}{c}\text { Short Final } \\
\text { Condition }\end{array}$} & & \multicolumn{2}{c}{$\begin{array}{c}\text { Long Final } \\
\text { Condition }\end{array}$} \\
\cline { 2 - 3 } \cline { 5 - 6 } Task & $\mathrm{T}$ & $S D$ & & $\mathrm{~T}$ & $S D$ \\
\hline Reading speed & 2.85 & 0.70 & & 2.88 & 0.72 \\
Operation speed & 2.16 & 0.54 & & 2.16 & 0.48 \\
Reading span & 4.24 & 0.70 & & 3.91 & 0.68 \\
Operation span & 5.48 & 1.01 & & 5.16 & 1.29 \\
\hline
\end{tabular}

analysis of variance (ANOVA) was conducted on the trial completion time with final card condition and working memory task as factors. There was no significant difference in the average card processing time for the long final and short final conditions $\left(F<1\right.$, partial $\left.\eta^{2}=.006\right)$. Adults were slower to work through reading cards than arithmetic operation cards $[F(1,29)=38.3, p<.01$, partial $\left.\eta^{2}=.569\right]$, and there was no interaction between these factors $\left(F<1\right.$, partial $\left.\eta^{2}=.001\right)$. As a further manipulation check, an ANOVA showed emphatically greater completion times for long cards ( 2.7 and 3.6 sec for operation and reading cards, respectively) relative to short cards $\left[1.6\right.$ and $2.5 \mathrm{sec} ; F(1,29)=292.9, p<.01$, partial $\eta^{2}=$ $.910]$, and again reading cards were more time-consuming than operation cards $\left[F(1,29)=48.3, p<.01\right.$, partial $\eta^{2}=$ $.625]$. The lack of interaction between working memory task and card length $\left(F<1\right.$, partial $\left.\eta^{2}=.002\right)$ suggests that in this study the length manipulation was equivalent for sums and sentence completions.

Analysis of the working memory span scores, also detailed in Table 1, showed that operation span scores were significantly higher than reading span scores $[F(1,29)=$ $55.8, p<.01$, partial $\eta^{2}=.658$ ]. Furthermore, the final card condition made a significant difference to span scores $\left[F(1,29)=10.5, p<.01\right.$, partial $\left.\eta^{2}=.266\right]$, with spans reduced by a longer retention interval (i.e., lower spans with a long final card). There was no interaction between final card and working memory span conditions $\left(F<1\right.$, partial $\left.\eta^{2}<.001\right)$.

The time to complete cards presented first and last (where the contents of the cards are equivalent but the concurrent memory demands differ) are given in Table 2. Analysis showed quicker responses to arithmetic operations than sentences $\left[F(1,29)=37.5, p<.01\right.$, partial $\eta^{2}=$ $.564]$ but no overall difference in processing speed $(F<1$, partial $\left.\eta^{2}=.006\right)$ and no significant interaction between these $\left[F(1,29)=2.10\right.$, partial $\left.\eta^{2}=.067\right]$. Memory load was not a determinant of processing duration.

The nature of the operation span materials provided the opportunity to pursue this issue further. Since short and long operations were presented not only in the first and last positions, but also sometimes in middle positions, analysis of response time at each phase was examined (data for long operations are reported because it was felt they might be more susceptible to load effects, although the two operation lengths produce very similar findings). The average completion times (standard deviations in parentheses) for these four-term problems were $2.62(0.7), 2.66$ (0.87), and $2.88(0.78)$ seconds for first, middle, and last cards, a nonsignificant difference $[F(2,58)=1.88$, partial $\left.\eta^{2}=.061\right]$.

The overall pattern of results described above also held true when we considered the reading span and the operation span tasks separately (and including completion order of final card condition as an additional experimental factor). In particular, span in the long final card condition was lower than for the short final condition for reading span $\left[F(1,28)=6.63, p<.05\right.$, partial $\left.\eta^{2}=.191\right]$ and for operation span $\left[F(1,28)=6.13, p<.05\right.$, partial $\left.\eta^{2}=.180\right]$. For reading span, there was a nonsignificant decrease in time spent on final cards [with a higher memory load; $F(1,28)=1.52$, partial $\eta^{2}=.052$ ], and for operation span there was a nonsignificant increase in time spent on the final cards $\left(F<1\right.$, partial $\left.\eta^{2}=.029\right)$. The incidental variable completion order produced no main effects and no interactions (all $p \mathrm{~s}>.10$ ).

In the main, adults were able to complete the arithmetic sums and complete sentences without error. For the reading span task, a total of 1,646 sentences were presented, of which only $52(<4 \%)$ yielded nonpredicted answers. Of these only five sentence responses were inappropriate, and since only one of the short and one of the long sentences produced inappropriate answers, the data give no reason to suppose the longer sentences were any more difficult.

Errors on the arithmetic operation task were more numerous, with 133 errors from 2,566 responses (an error rate of $5.2 \%$ ). The error percentages (and standard deviations) on first, middle, and final card positions were 4.00 (6.76), 6.25 (5.80), and $7.26(7.96)$, respectively, and these values failed to reach significance by Friedman one-way analysis of ranks $\left[\chi^{2}(2, N=30)=5.12, p=.08\right.$ (parametric analysis also showed a nonsignificant change across positions, $p>.10$, partial $\left.\left.\eta^{2}=.061\right)\right]$. Comparison of the error rate (mistakes per unit time) on both first and last cards showed that long problems generated more errors than short problems $(z=2.4, p<.05)$. However, response times for long problems yielding errors were equivalent to response times for long problems with correct solutions $\left[t(18)=1.17, p>.10, \eta^{2}=.067\right]$. This latter finding suggests that miscalculations were not necessarily due to difficult and therefore slow operations (see also error analysis below). One alternative is that participants were susceptible to occasionally "estimating" an-

Table 2

Time to Complete Processing Operations (T, in Seconds) and Standard Deviations as a Function of Position Within a Series of Operations for Reading and Operation Span

\begin{tabular}{lccccc} 
& \multicolumn{2}{c}{ First Card in Set } & & \multicolumn{2}{c}{ Last Card in Set } \\
\cline { 2 - 3 } \cline { 5 - 6 } Task & $\mathrm{T}$ & $S D$ & & $\mathrm{~T}$ & $S D$ \\
\hline Reading & 3.09 & 0.81 & 2.99 & 0.74 \\
Arithmetic & 2.22 & 0.48 & 2.28 & 0.57 \\
\hline
\end{tabular}


Table 3

\begin{tabular}{|c|c|c|c|c|c|c|}
\hline \multicolumn{7}{|c|}{ Intercorrelations Between Performance Measures } \\
\hline Variable & 1 & 2 & 3 & 4 & 5 & 6 \\
\hline \multicolumn{7}{|l|}{ 1. Reading span } \\
\hline 2. Reading speed & -.024 & & & & & \\
\hline 3. Operation span & ${ }^{* *} .547$ & -.171 & & & & \\
\hline 4. Operation speed & .385 & .380 & .082 & & & \\
\hline 5. Operation errors & -.152 & -.207 & -.311 & -.099 & & \\
\hline 6. Identical pictures test speed & .140 & .135 & .104 & .169 & -.273 & \\
\hline 7. Digit comparison test speed & -.268 & .173 & -.221 & .038 & .151 & .006 \\
\hline
\end{tabular}

swers when attempting to progress toward the recall phase of the task. For example, one participant repeatedly produced " 0 " in answer to a short problem " $6-0=$," implying a failure to engage fully in the task. Impatience at resolving the more involved, four-term, problems can account for the higher error frequency.

\section{Individual Difference Analysis}

Table 3 details the zero-order correlations between measures of working memory span (a composite of $z$ score transformations for short final and long final spans), working memory speed (average time to respond to all cards), the proportion of errors on the operation span task (errors were too low in the reading span task to make analysis meaningful), and processing speed (noted separately for the identical picture and number comparison tests). Reliability of the composite measures was high insofar as the component scores were related, with $r s$ ranging between .53 and .84 (all $p s<.01$ or better). There were no multivariate outliers as measured by Mahalanobis distances and no substantial skew for any of the variables ( $z$ ranging between -0.2 and 1.8). A single univariate outlier was found for the digit-matching task $(z>4)$ and for reading $\operatorname{span}(z>3)$, and these scores were excluded, though in neither case did this materially affect the data pattern.

Whereas the two measures of working memory showed a reliable correlation, there was no significant relationship between the on-line measure of speed and span performance, or with task-external measures of processing speed. Nonetheless, it is not the case that among the adult data, the associations between variables are just weaker, since the correlation between reading span and operation span here is higher than that reported for children [Towse et al., 1998; $r(60)=.37]$.

A prediction of the resource-sharing model is that difficult problems should be associated with poor memory performance (there being a tradeoff between memory and processing difficulty), and thus a high proportion of errors, as a signal of cognitive overload, would lead to lower working memory span scores. Although this relationship could also be mediated by other factors (any general ability driving up span and driving down errors), the correlation between operation processing errors and operation span was not significant. Furthermore, the more specific correlation between the proportion of errors on the long final card and the operation span for the long final condition was not significant either $[r(28)=-.26, p>$ $.10]$. In other words, indices of processing demand (errors) were not strongly associated with memory performance.

The findings concerning working memory task speed and working memory span contrast with significant correlations obtained among children using exactly the same materials. Comparisons of the speed-span relationship between children described in Towse et al. (1998, Experiment 3 ) and the adults described here, after making appropriate Fisher's $r$ ' transformation, shows a significantly stronger correlation among children $(z=2.13$ and $z=$ $2.90)$ for operation span and reading span, respectively $(p s<.05)$. However, the speed-span correlation in children was also related to their age, and so comparisons were made after partialing out age in both children and adult data sets. The speed-span relationship for the operation task was still more evident for children than for adults, but this effect was only marginally significant (2tailed test, $z=1.77, p<.10$ ). For the reading task, the speed-span relationship remained significantly stronger for children than adults $(z=3.04, p<.01)$.

\section{DISCUSSION}

The present results show that, as a broad picture, the working memory span tasks used here show a close correspondence. The working memory span tasks exhibit a healthy correlation with each other. Both operation span and reading span are significantly affected by the retention duration of items. For neither span task does the size of the memory load affect the completion time for the processing activity. Finally, both working memory span scores were unrelated to the rate at which processing was completed, or task-independent measures of speed. Except for the final analyses, results closely mirror those obtained with children (Towse et al., 1998).

We do not wish to argue by extension that working memory span tasks are entirely interchangeable (e.g., see Hitch, Towse, \& Hutton, in press). Nonetheless, the data provide support and extension for the task-switching model. According to this approach, working memory span reflects the gradual degradation of memory representations during the time spent on the requisite cognitive processing task rather than as a function of processing intensity (see also Duff \& Logie, in press; Halford 
et al., 1994; Towse \& Hitch, 1995). As pointed out previously (Towse et al., 1998), the present approach cannot directly address the question of whether time per se produces the loss of information from working memory, or whether there are processes such as intralist interference that operate over time (see Hasher \& Zacks, 1988, and Rosen \& Engle, 1998, for consideration of how aspects of interference may be relevant to working memory). It is conceivable that research may culminate in time being seen as a marker for other causal processes. This would not detract from the thrust of the present work, however, in moving away from simple resource sharing as an explanatory construct and moving toward (among other things) a greater consideration of the temporal dynamics of working memory tasks.

In the operation span task, data also showed that errors occurred at a faster rate on long arithmetic problems than on short arithmetic problems. One consideration, then, is whether long operations are to be regarded as more cognitively demanding (rather than just slower), with this extra difficulty being responsible for the decline in span in the long final condition. This interpretation is not the only one (e.g., see Results section), nor is it consistent with the absence of a strong correlation between error proportions and span scores; nor does it explain children's performance where long operations were not more error prone. Moreover, even leaving aside these objections, such an argument overlooks the fact that a long operation is also present as the initial card in the small final condition. These initial long cards ought to affect retention also, if processing and storage are interdependent. Indeed, in terms of cognitive demand, the proactive effects from the first card might be more important than the retroactive effects from the last card. Further still, since reading span data did not provide evidence for differential processing difficulty on short and long cards, this account can in any case only possibly apply to one of the two working memory span tasks. All of which is in contrast to the interpretation favored here, consistent with the wider body of data, that what critically distinguishes the short final and the long final condition is the retention interval of the memory items.

Notwithstanding the essential replication of data from children, the present findings show that some of the conclusions made by Towse et al. (1998) were misplaced. Developmental evidence for task switching and against resource sharing was contrasted with adult data (e.g., Engle et al., 1992) inconsistent with processing-speed accounts of working memory span. This was taken to suggest the possibility that there may be a developmental discontinuity in mental strategies, with children using serial or independent processes and adults using general processes. The present findings, in showing an effect of retention duration but an insensitivity of processing to memory load, imply that this conclusion was incorrect. In terms of the experimental effects, adults behave in a quite similar way to children previously considered.
This may be seen to leave something of a puzzle. If the reading and operation span performance of adults in the present experiment is not qualitatively different from that of children, how does one reconcile these data with previous suggestions that adults share processing and storage resources in working memory span tasks? At least three possibilities can be considered.

First, it may be wondered whether the manipulation of retention interval affected putative resource-sharing strategies in a quite intricate way. Thus, one reviewer suggested that dynamic resource sharing might occur, with the ratio of storage to processing resources changing through the set of cards in such a way as to affect resource availability for memory without affecting the measure of resource availability for processing, card completion time. We accept that it may be possible to attempt such theoretical gymnastics, just as we accept that some analyses showed trends in the direction predicted by a simple resource-sharing model (although the predictions are not always unique to it). The problem with complex accounts such as this is that they have very little independent support (i.e., they are highly post hoc), do not readily submit to empirical evaluation, and seem to serve largely as a reminder of the theoretical looseness in the concept of resources.

Second, Caplan and Waters (1999) have recently reviewed experimental work on syntactic processing and working memory, including several studies often taken as supporting the notion of a general processing-storage tradeoff. One of their conclusions is that there is rather little unequivocal evidence that syntactic processing and memory compete for shared resources, whether one considers the normal adult population, neuropsychological studies following aphasia, or senile dementia of the Alzheimer's type. In other words, the notion of resource sharing in adults as a ubiquitous strategy can be subject to reinterpretation.

Third, we suggest that an important and unanticipated clue to working memory span performance is found in the absence of correlations between speed and span that stands in contrast to children's performance and in contrast to experimental effects. That is, both for children and adults, retention interval affects span. For children, span correlates with the rate at which processing is carried out, but among adults this is not the case. Given the reliable difference in the strength of correlations between children and adults, this cannot be thought of as merely an issue about small sample sizes in testing adults.

Given these correlational data, one needs to ask the question: What underlies the categorization of individuals as having high working memory span or low working memory span? The common answer to this question is that a high span individual possesses a large working memory capacity and a low span individual a small working memory capacity, with capacity referring to the ability to engage in some form of resource sharing between storage and processing functions. While this is a prevalent 
orthodoxy, one can propose several mechanisms other than resource sharing to underpin these individual differences (e.g., see Towse, Hitch, \& Hutton, 1999). Furthermore, Byrne (1998) has provided a computational simulation of age-related decline in working memory tasks without a resource-sharing capacity at its core. We suggest that simulations of this type, as well as the present data, raise challenges for the interpretation of adult studies comparing high and low span groups. Specifically, studies that essentially correlate some cognitive measure with working memory performance (taking the end points of the high and low span continuum) may overlook the role of variables that can be shown to have substantial experimental and computational power. Even when these variables do not take a direct role in influencing working memory span, an indirect role cannot be, at this point, excluded.

For several reasons, then, the individual-difference approach comparing high and low span performers that has characterized much research may not provide a firm foundation for theory building without convergent evidence to support it. First, current data considerably undermine the notion that resource sharing necessarily occurs in the working memory span task among adults; the explanatory value of the framework appears limited. Second, the data support a view that forgetting over time influences working memory span, an issue that is often neglected in theoretical accounts, but with potential implications for interpreting individual differences. Third, insofar as individual differences in span are not related to processing rate in a direct way, the present data imply that there are further factors at play underlying the differences between low and high span individuals. The possible variety of influences shaping working memory span clearly merits further research.

In conclusion, the present experiment has been helpful in extending previous work among children of different ages. The data show that many of the findings from children do hold among adults, though there are differences, too. The findings suggest that working memory span, assuming it can be measured accurately and reliably (for a consideration, see Waters \& Caplan, 1996), is not a pure measure of working memory capacity. While we do not dissent from the view that working memory span predicts various important aspects of cognitive performance (on the basis of empirical demonstration; see Daneman \& Carpenter, 1980; Tirre \& Peña, 1992; Turner \& Engle, 1989), we lack complete explanations for why this is so. The present data provide further support for the taskswitching model of working memory span. At the same time, these results illustrate how this model, too, is incomplete, and needs to be developed alongside other concepts to furnish an adequate account of working memory span performance.

\section{REFERENCES}

Adams, J. W., \& Hitch, G. J. (1997). Working memory and children's mental addition. Journal of Experimental Child Psychology, 67, 21-38.

BADDELEY, A. D. (1986). Working memory. Oxford: Oxford University Press, Clarendon Press.
Baddeley, A. D., \& Hitch, G. J. (1974). Working memory. In G. Bower (Ed.), The psychology of learning and motivation: Advances in research and theory (Vol. 8, pp. 47-89). New York: Academic Press.

BYRNE, M. D. (1998). Taking a computational approach to aging: The SPAN theory of working memory. Psychology \& Aging, 13, 309-322.

CAPLAN, D., \& Waters, G. S. (1999). Working memory and sentence comprehension. Behavioral \& Brain Sciences, 22, 77-126.

Case, R., Kurland, M., \& GoldberG, J. (1982). Operational efficiency and the growth of short-term memory span. Journal of Experimental Child Psychology, 33, 386-404.

CONWAY, A. R. A., \& ENGLE, R. W. (1994). Working memory and retrieval: A resource-dependent inhibition model. Journal of Experimental Psychology: General, 123, 354-373.

Conway, A. R. A., \& EngLE, R. W. (1996). Individual differences in working memory capacity: More evidence for a general capacity theory. Memory, 4, 577-590.

Craik, F. I. M., \& Tulving, E. (1975). Depth of processing and the retention of words in episodic memory. Journal of Experimental Psychology: General, 104, 268-294.

Daneman, M. (1995). [Review of the book Working memory and severe learning difficulties]. American Journal of Psychology, 108, 464470.

Daneman, M., \& Carpenter, P. A. (1980). Individual differences in working memory and reading. Journal of Verbal Learning \& Verbal Behavior, 19, 450-466.

DANEMAN, M., \& CARPENTER, P. A. (1983). Individual differences in integrating information between and within sentences. Journal of Experimental Psychology: Learning, Memory, \& Cognition, 9, 561-584.

DufF, S., \& LoGie, R. (in press). Processing and storage in working memory span. Quarterly Journal of Experimental Psychology.

Ekstrom, R. B., French, J. W., Harmen, H. H., \& Dermen, D. (1976) Manual for kit of factor-referenced cognitive tests. Princeton, NJ: Educational Testing Service.

ENGLE, R. W. (1996). Working memory and retrieval: An inhibitionresource approach. In J. T. E. Richardson, R. Engle, L. Hasher, R. Logie, E. Stolzfus, \& R. Zacks (Eds.), Working memory and cognition (pp. 89-120). New York: Oxford University Press.

Engle, R. W., Cantor, J., \& Carullo, J. J. (1992). Individual differences in working memory and comprehension: A test of four hypotheses. Journal of Experimental Psychology: Learning, Memory, \& Cognition, 18, 972-992.

Engle, R. W., Tuholski, S. W., Laughlin, J. E., \& Conway, A. R. A. (1999). Working memory, short-term memory and general fluid intelligence: A latent variable approach. Journal of Experimental $P$ sychology: General, 128, 309-331.

Halford, G. S., Maybery, M. T., O'Hare, A. W., \& Grant, P. (1994). The development of memory and processing capacity. Child Development, 65, 1330-1348.

HASHER, L., \& ZACKS, R. T. (1988). Working memory, comprehension, and aging: A review and a new view. In G. H. Bower (Ed.), The psychology of learning and motivation: Advances in research and theory (Vol. 22, pp. 193-225). New York: Academic Press.

Hitch, G. J., \& BADDELEY, A. D. (1976). Verbal reasoning and working memory. Quarterly Journal of Experimental Psychology, 28, 603621.

Hitch, G. J., Towse, J. N., \& HutTon, U. (in press). What limits children's working memory span? Theoretical accounts and applications for scholastic development. Journal of Experimental Psychology: General.

Hutton, U., Towse, J. N., \& Hitch, G. J. (1997). Children's competence at solving arithmetic operations in a working memory task (Tech. Rep. No. CDRG2). University of London, Royal Holloway.

KyLlonen, P. C., \& CHRISTAL, R. E. (1991). Reasoning ability is (little more than) working memory capacity?! Intelligence, 14, 389-433.

LA Pointe, L. B., \& EnGle, R. W. (1990). Simple and complex word spans as measures of working memory capacity. Journal of Experimental Psychology: Learning, Memory, \& Cognition, 16, $1118-1133$.

MiYAKe, A., JUST, M. A., \& CARPENTER, P. A. (1994). Working memory constraints on the resolution of lexical ambiguity: Maintaining multiple interpretations in neutral contexts. Journal of Memory \& Language, 33, 175-202. 
Rosen, V. M., \& ENGLE, R. W. (1998). Working memory capacity and suppression. Journal of Memory \& Language, 39, 418-436.

TiRre, W. C., \& PEÑA, C. M. (1992). Investigation of functional working memory in the reading span test. Journal of Educational Psychology, 84, 462-472.

Towse, J. N., \& Hiтch, G. J. (1995). Is there a relationship between task demand and storage space in tests of working memory capacity? Quarterly Journal of Experimental Psychology, 48A, 108-124.

TowSE, J. N., Hitch, G. J., \& Hutron, U. (1998). A reevaluation of working memory capacity in children. Journal of Memory \& Language, 39, 195-217.

Towse, J. N., Hitch, G. J., \& Hutton, U. (1999). The Resource King is dead! Long live the Resource King! Behavioral \& Brain Sciences, 22, 111 .

Towse, J. N., Hutton, U., \& Hitch, G. J. (1997). Humpty Dumpty had a great . . banana? Children's sentence completions on a working memory reading task (Tech. Rep. No. CDRG1). University of London, Royal Holloway.
TURner, M. L., \& ENGLE, R. W. (1989). Is working memory capacity task dependent? Journal of Memory \& Language, 28, 127-154.

WATERS, G. S., \& CAPLAN, D. (1996). The measurement of verbal working memory capacity and its relation to reading comprehension. Quarterly Journal of Experimental Psychology, 49A, 51-70.

\section{NOTE}

1. Although simple span and complex span are useful heuristic labels, they do presuppose that tasks like digit span are somehow more basic, or free from strategic deployment. Since these tasks are often intricate and sensitive to subtle effects and changes, these labels have connotations that may be rather misleading in some respects.

(Manuscript received August 24, 1998; revision accepted for publication April 29, 1999.) 